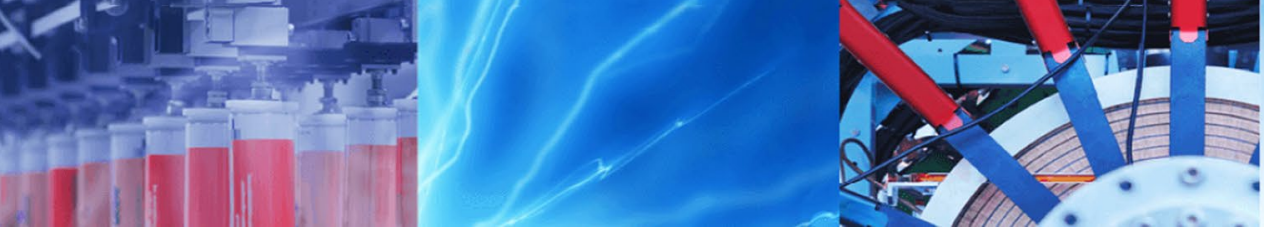

Research Article

\title{
Classification of rock types using multivariate analysis in the Dezak area, SW Iran
}

\author{
Ghazal Hajnajafi $^{1}$ [D $\cdot$ Alireza Jafari-Rad ${ }^{1} \cdot$ Peyman Afzal $^{2} \cdot$ Seyed-Jamal Sheikh-Zakariaee $^{1}$
}

Received: 2 April 2020 / Accepted: 18 August 2020 / Published online: 13 September 2020

(c) Springer Nature Switzerland AG 2020

\begin{abstract}
The geochemical multivariate techniques were applied to recognize different geological units and categorized rock types which accompanied by different penalties. Knowing changes and classification of raw materials with macroscopic and microscopic quantification have direct effect on economic and efficiency in a precipitated calcium carbonate plant. Based on lithological changes, the Darian Formation was divided into four rock units based on a total of 492 chip samples collected from the study area. The main aim objective of this study was to classify the rock types in this area using a multivariate analysis combining the $\mathrm{R}$-mode factor analysis and $\mathrm{K}$-Means method. Due to the opposite vector orientation of $\mathrm{SiO}_{2}, \mathrm{Al}_{2} \mathrm{O}_{3}, \mathrm{Fe}_{2} \mathrm{O}_{3}, \mathrm{~K} 2 \mathrm{O}, \mathrm{MgO}, \mathrm{Na}_{2} \mathrm{O}, \mathrm{MnO}, \mathrm{TiO}_{2}, \mathrm{P}_{2} \mathrm{O}_{5}, \mathrm{SrO}$, and $\mathrm{SO}_{3}$ versus $\mathrm{CaCO}_{3}$, the lowest geochemical similarity and maximum separation distance were observed between $\mathrm{CaCO}_{3}$ and other parameters using the R-mode factor analysis, which has also been verified by the Ward's hierarchical agglomerative clustering method. Complementary Q-mode analysis was applied to determine the position of the samples (eigenvalues) with respect to the variables (eigenvectors). In order to geochemical classification of the samples, the K-Means clustering method classified the samples taken from the study area into four geochemical groups. The second group, which comprised a total of 422 composite samples, contained high-concentration $\mathrm{CaCO}_{3}$ samples with an average concentration greater than $97 \%$. The average $\mathrm{SiO}_{2}$ concentration in these samples was $1 \%$, and the sum of $\mathrm{Al}_{2} \mathrm{O}_{3}$ and $\mathrm{Fe}_{2} \mathrm{O}_{3}$ was about $0.38 \%$. Therefore, the materials falling in this group can be appropriately used as raw materials to feed the plant. Using clr-transformed data for R-and Q-mode analysis, the eigenvectors and eigenvalues show sub-compositionally coherent and closure effect is overcomes. The total variance which is explained by the first factor decreases from $78.6 \%$ in real R-mode analysis to $61.7 \%$ in clr transformation. Due to major occurrence of the first dimension on geochemical changes, the samples categorized as richest (the best data set), contaminated (the worst data set), and transmission zone.
\end{abstract}

Keywords Dariyan Formation · R-mode factor analysis · K-Means clustering · Precipitated calcium carbonate (PCC) · Micritic and crystallized limestone $\cdot$ Clr transformation

\section{Introduction}

Although the limestone formation is widely extended across Iran, not many areas are available from which precipitated calcium carbonate (PCC) can be industrially produced. The PCC is the most important product produced from limestone mineral processing [41]. This product is used in a variety of industries including pharmaceuticals, paper industries, and cosmetics [23]. Papers made from $\mathrm{CaCO}_{3}$ have a low production cost and high quality and offer advantages such as environment-friendly properties, reduced water consumption, higher printing resolutions,

$\triangle$ Alireza Jafari-Rad, alirad@yahoo.com; Ghazal Hajnajafi, ghazal.hajnajafi@gmail.com; Peyman Afzal, peymanafzal@gmail.com; Seyed-Jamal Sheikh-Zakariaee, j.sheikhzakaria@gmail.com | ${ }^{1}$ Department of Earth Science, Science and Research Branch, Islamic Azad University, Tehran, Iran. ${ }^{2}$ Department of Petroleum and Mining, South Tehran Branch, Islamic Azad University, Tehran, Iran. 
increased resistance, waterproof properties, and resistance to oil and insects [26]. Therefore, the PCC industry plays an important role in the paper production across the world. To prepare PCC, high-purity limestone reserves must be available in large amounts. Moreover, the extracted materials should a minimum amount of penalty elements such as silicic components and $\mathrm{Fe}_{2} \mathrm{O}_{3}$, and suitable infrastructure and conditions should be provided for the mining processes [25].

The Dezak limestone area is located at $30 \mathrm{~km}$ southeast of Shahrekord, in Charmahal-va-bakhtiari provinces, SW Iran [14]. The Dariyan Formation in the High Zagros zone is strongly covered by shallow limestone with wackstone-packstone textures preserved from the lower Cretaceous. It is composed of medium-bedded gray limestone. The lower and upper boundaries gradually transition to the Fahliyan and Kazdomi Formations, respectively. This area is a potential site for industrial survey project of PCC. A systematic sampling was designed in order to identify the properties of the rock units. The results from XRF analysis were interpreted by the multivariate and univariate analyses. Due to the compositional specification of the variables and existence of penalties, the selection of the $\mathrm{CaCO}_{3}$-richest materials is not the only goal. Based on compositional properties of the data in geochemical processes, the samples and variables must be interpreted simultaneously. Therefore, multivariate analysis would be applied in order to identification of $\mathrm{CaCO}_{3}$-rich zone with a minimum amount of penalty elements. Accordingly, R-mode and Q-mode analysis and K-Means methods could help to explore the relationship between elements and samples. Factor analysis (FA) and the cluster and K-Means analyses are the most frequently used multivariate methods in the literature to explore the relationship between elements and samples [21, 22, 34]. These methods are employed to reduce the dimension for variability between data sets [9, 43]. In this manuscript, the clr-transformed data have been used by robust R-mode analysis, while they obtained by the CoDaPack software v 2.01 (available at http://www. compositionaldata.com/). The compositional data in geochemical samples reveal the nonnegative value for elements (indicated as vectors in R-mode graphical outcomes) and sum to a constant [38].

From a tectonic point of view and considering the sedimentary facies and structural style in SE Iran, the Darian, Gadvan, and Kazhdumi are the essential formations in the Dezak area, SW Iran [7]. The lower boundary of the Darian Formation gradually fades and reaches the Gadvan Formation, but from above it is strongly eroded with Kazhdomi Formation and separated by the oolitic and glauconite layers [19]. The Dariyan limestone separates the Gadvan (below) and Kazhdumi (above) Formations. This formation is known as a part of the Cretaceous (Lower Cretace) sequence in the southwest of Iran [32]. Darian is the most important reservoir in the Zagros basin for hydrocarbon accumulations southwest of Iran [27]. The Shaiba Formation south of Persian Gulf can be considered a similar formation located in the countries in this region [30, 37]. The Darian Formation includes about 286.5-m-thick brown-gray limestone abundant with orbitalina [33].

The first major goal of the study was the identification and classification rock types in the Dezak area based on the geochemical data and using a multivariate analysis combining the R-mode analysis and K-Means methods. The geological evidence and specimen properties must be consistent in the geochemical analysis. To this end, a $\mathrm{CaCO}_{3}$-rich zone with a minimum amount of penalty elements must be identified, for which the following steps should be taken: (1) exploration of the best lithologies that cover the main concepts, (2) identification of distinct rock unites both geologically and geochemically, and (3) area classification based on the amount of the main components so as to provide an appropriate feed zoning.

\section{Geological setting}

The exploration operations around the village of Dezak in Chaharmahal and Bakhtiari Province began in late 2016 to identify and supply raw materials to the PCC plant. The location map of the Dezak limestone exploration area in structural map of Iran is shown in Fig. 1. Prior to this, the prospecting and exploration phases were completed in an area of $15 \mathrm{~km}^{2}$ (1:10,000 scale) along with a semi-detailed exploration in a $2-\mathrm{km}^{2}$ area (south east of the preliminary exploration area). This basic exploration area is depicted by a red polygon. Moreover, the figure shows the two exploration license areas (highlighted in pink) and the area considered for the detailed exploration phase (marked by a yellow polygone covering 150 hectares).

The geological map of Dezak (scale 1:1000) for the detailed exploration phase is depicted in Fig. 2. The map covers an area of 150 hectares. The topography of the area is highly irregular as it is located on the margin of the main Zagros fault zone. The overall lithological sequences contain cretaceous sediments from Darian and Kazhdomy Formations. Based on lithological changes, the Darian and Kazhdumi Formations were divided into 4 and 1 units, respectively.

Thick-bedded to massive light gray to gray recrystallized and micrite limestone with intercalations of thin-bedded orbitolina limestone contains orbitolina and bivalves fossils and is indicated by $K_{d}^{l}$ unit. Thick- to medium-bedded light gray to gray limestone with intercalations of thin-bedded marl was introduced as $K_{d}^{\mathrm{Im}}$. The boundary of the $K_{d}^{l}$ and $K_{d}^{\mathrm{Im}}$ units on the west side of the 

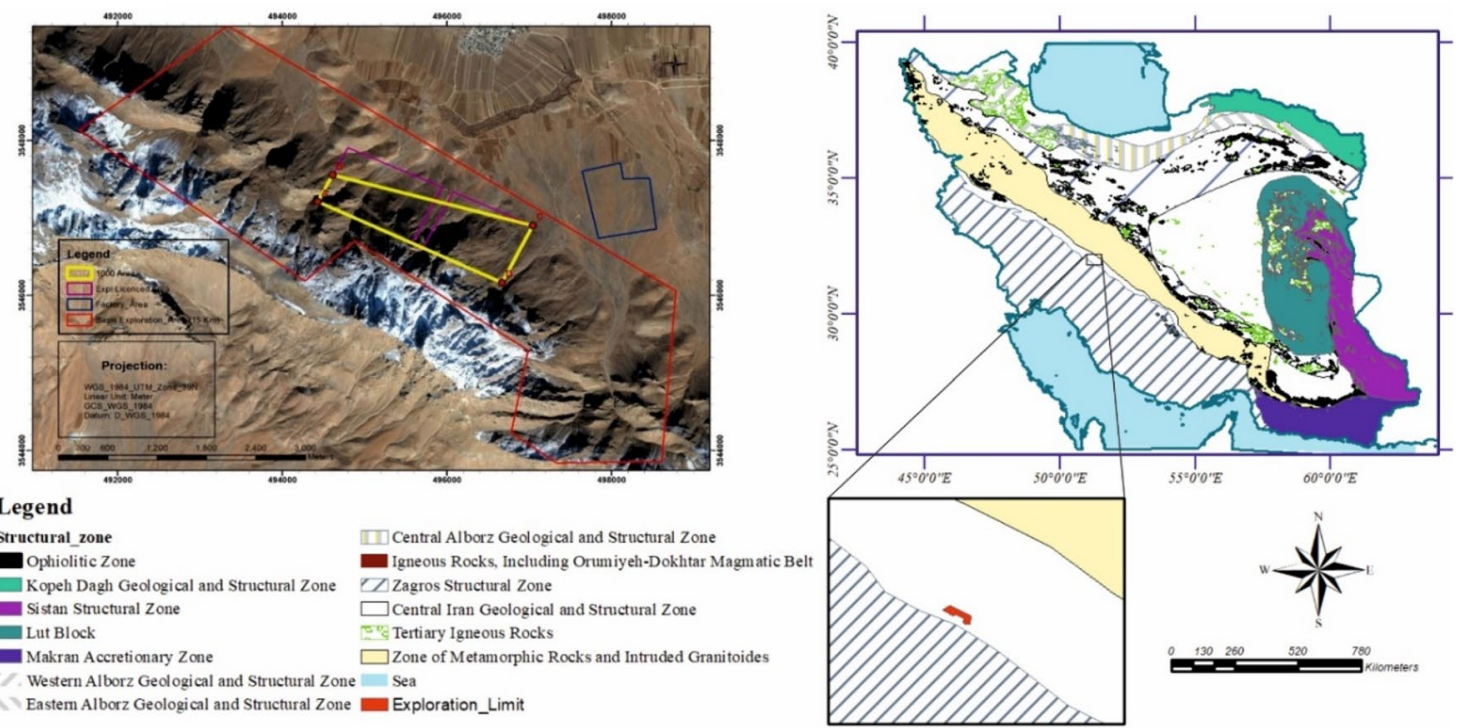

Fig. 1 Location map of the Dezak limestone exploration area in structural map of Iran. Yellow box: The area for the detailed exploration phase covering 150 hectares. Purple boxes: Exploration license areas. Red box: Preliminary exploration phase in an area of $15 \mathrm{~km}^{2}$. Blue box: Location of the designed factory

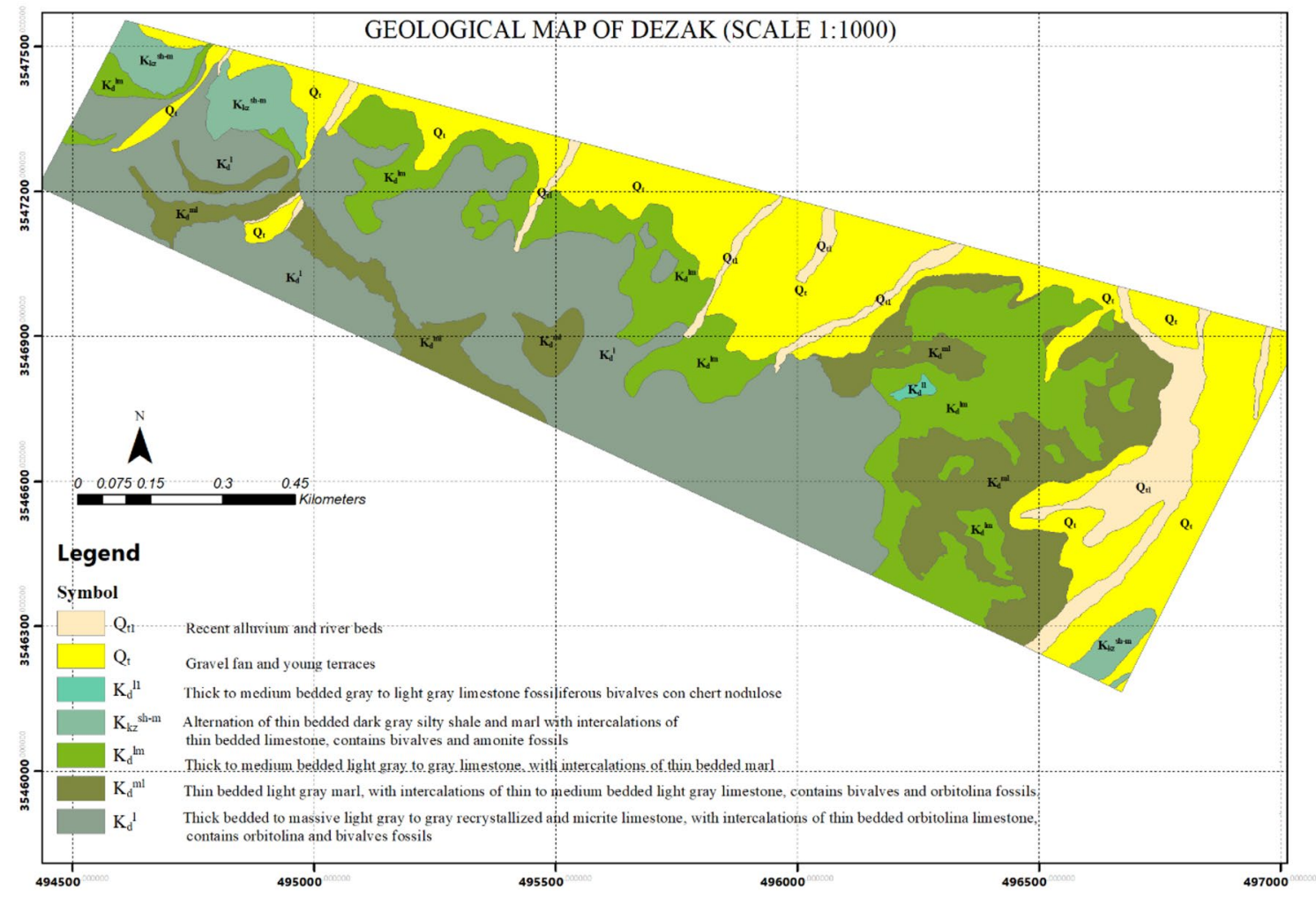

Fig. 2 Geological map of the Dezak area (scale 1:1000)

detailed exploration area is shown in Fig. 3a. Different views of the limestone layers in the area are depicted in Fig. 3b-d. Thin-bedded light gray marl with intercalations of thin- to medium-bedded light gray limestone contains bivalves and orbitolina fossils and is denoted by $K_{d}^{\mathrm{ml}}$. Thick- to medium-bedded gray to light gray limestone fossiliferous bivalves include chert nodulose 

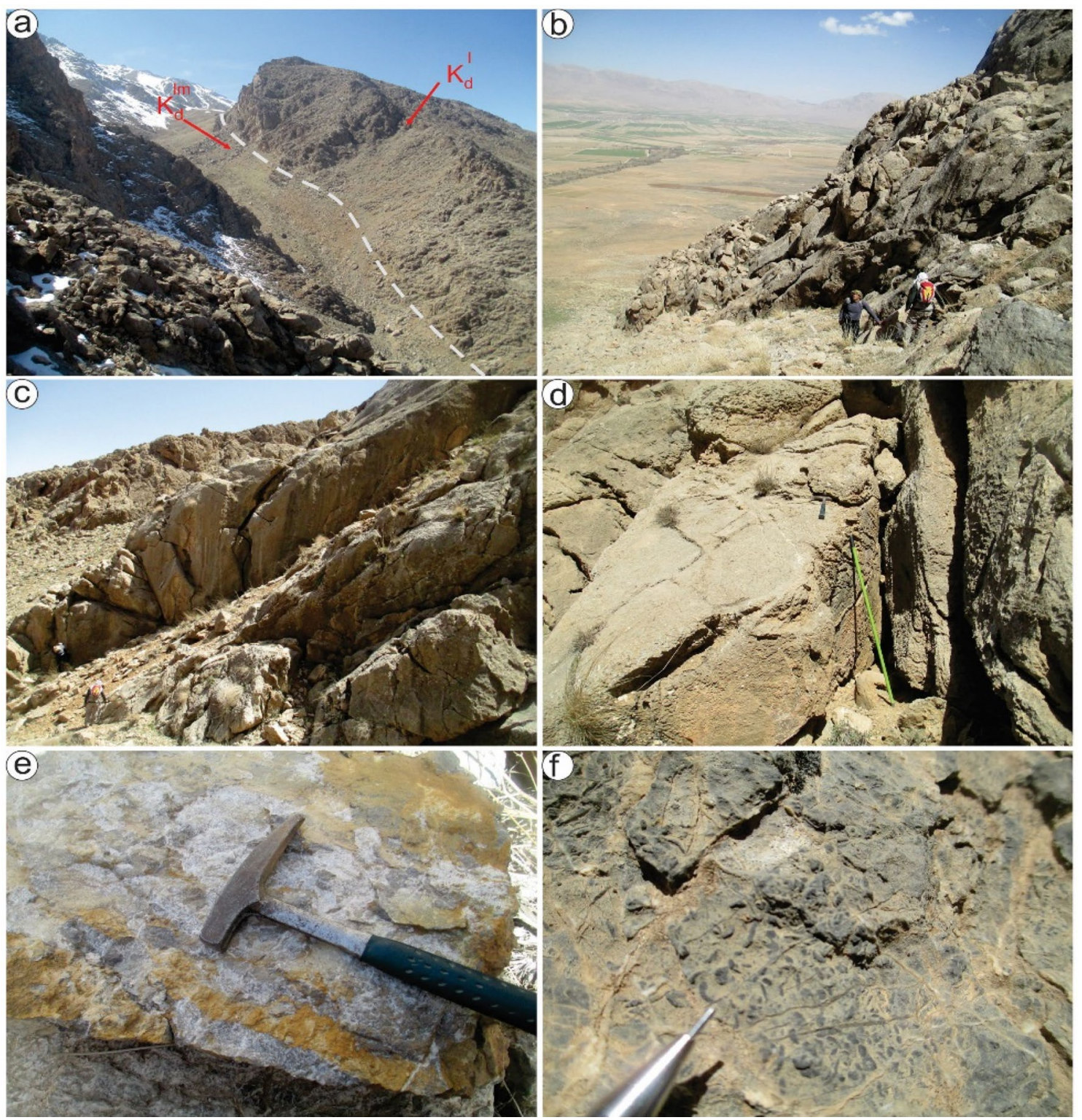

Fig. 3 a Boundary of the limestone and the marl with interbeded limestone unit on the west of the detailed exploration area, $\mathbf{b}$ a view of the limestone layers in the center of the area, $\mathbf{c}, \mathbf{d}$ different views of the limestone layers on the east of the area, $\mathbf{e}$ a view of the iron oxide veins inside the limestone layers, $\mathbf{f}$ a view of the orbitolina fossils found within the limestone layers and are presented by $K_{d}^{\|}$unit. Alternation of thin-bedded dark gray silty shale and marl with intercalations of thin-bedded limestone contains bivalves and amonite fossils, which are associated with the Kazhdumi Formation, and is indicated by $K_{k z}^{\text {sh-m }}$. Gravel fan and young terraces $\left(Q_{t}\right)$ and recent alluvium and river beds $\left(Q_{t t}\right)$ are the other recent sediments (Fig. 2). Iron oxide veins in slight amounts have been observed inside the limestone layers (Fig. 3e). Orbitolina fossils found within the limestone layers in $K_{d}^{l}$ and $K_{d}^{\mathrm{Im}}$ units are depicted in Fig. $3 \mathrm{f}$.

\section{Materials and methods}

\subsection{Sampling and stratigraphic column}

Systematic sampling was carried out for carbonate rocks and other units using a regular grid of $40 \mathrm{~m} \times 40 \mathrm{~m}$. Multiple chip samples were collected from each square box, and all samples were packed as a composite sample (Fig. 4). Each box corresponding to a laboratory sample, a total of 492 samples (originated from 2024 chip sample) were collected from the area. Due to the impossibility of sampling, some of the considered samples were not 
Fig. 4 Systematic sampling of area in the exploration phase. The profile of Seghalat (name of the valley) is schematically

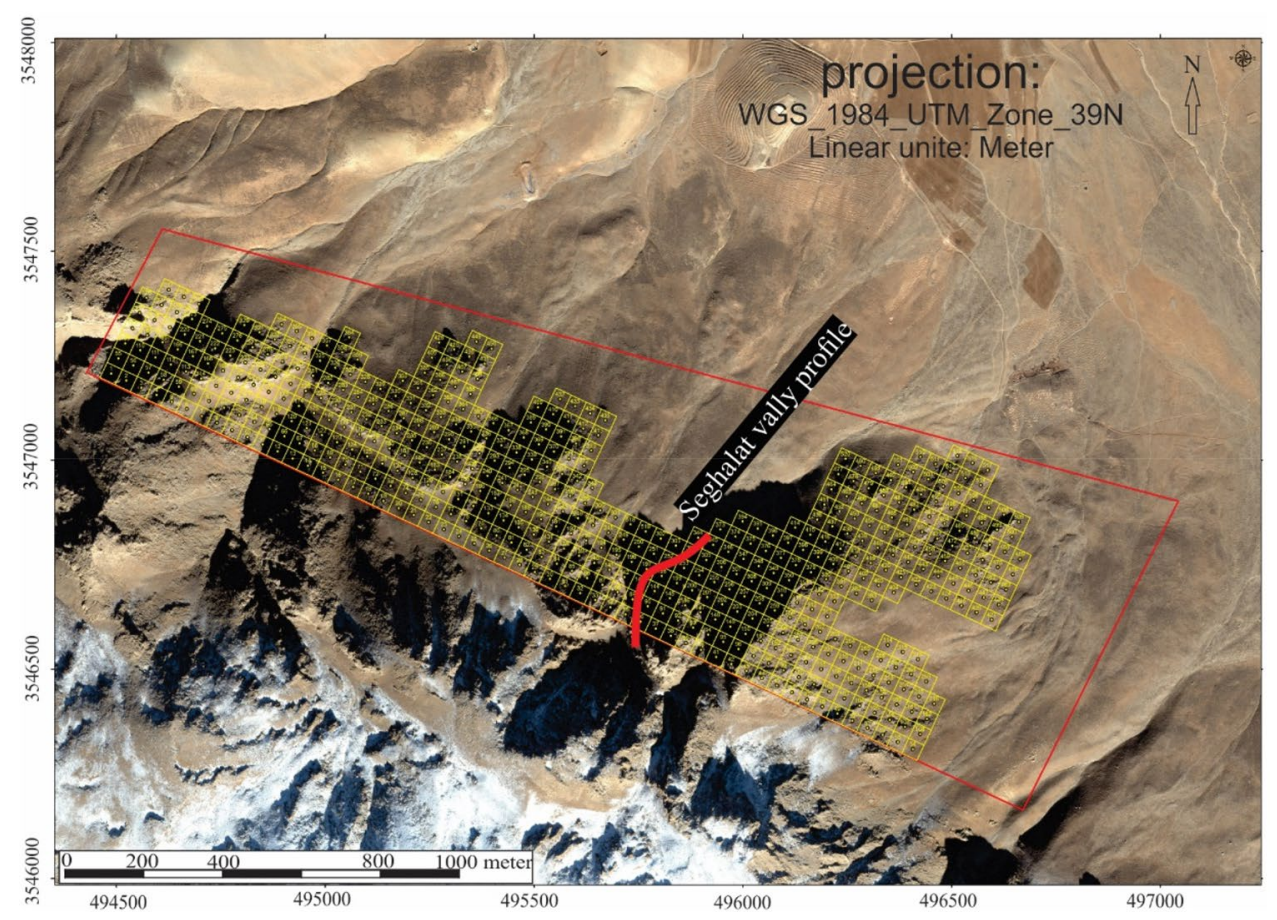

Table 1 Classified types for the field samples in the exploration phase

\begin{tabular}{lcc}
\hline Sample type & Total samples & $\begin{array}{l}\text { Final } \\
\text { composite } \\
\text { samples }\end{array}$ \\
\hline $\begin{array}{l}\text { Crystallized and micritic } \\
\text { limestone samples }\end{array}$ & 1890 & 421 \\
$\begin{array}{l}\text { Marl samples } \\
\text { Limestone and marl } \\
\quad \text { (mixed sample) }\end{array}$ & 98 & 62 \\
Chert-limestone & 8 & 7 \\
\hline
\end{tabular}

extracted during the sampling operation. Finally, a total of 421 samples were taken from the crystallized and micritic limestone, 62 samples from the marl unit, 7 samples from the limestone and marl (mixed sample) units, and 2 samples from the chert-limestone rocks (Table 1). All samples were subjected to $X$-ray fluorescence analysis (XRF) to measure their major oxides.

Moreover, the Seghalat profile was designed to plot a stratigraphic column over the area. The position of this profile is shown in Fig. 4. Overall, eight samples were taken from 10KLED063 to 10KLED070, each composed of several subsamples (Fig. 5). The actual thickness of the stratigraphic unit $(\mathrm{m})$ varied from 10 to $60 \mathrm{~m}$ (as minimum and maximum, respectively), with a total thickness of roughly $177 \mathrm{~m}$ (Fig. 6). Important notes regarding each lithology in this stratigraphic column are given in Fig. 6.

\subsection{Compositional data analysis}

Regarding the statistical methods, there are several normalization schemes for compositional data that should probably be applied here prior to any clustering or factor analysis. According to specification of geochemical data and their spatial distribution, the closure effect is not avoided for real data. In order to avoid the closure effect of element, the data should be opened using log-ratio transformation $[6,10,15,17,28]$. The clr, the ilr, and alr transformation are the different type of log-ratio transformation $[5,8,36,44]$. The alr and clr transformations were already defined by Aitchison [5]. One example normalization technique is the centered log-ratio (clr) method, but there are several others (isometric log-ratio is another). Methods, applications, and calculation software for these normalization schemes are readily available for free online (e.g., CoDaPack).

\subsection{Hierarchical clustering and R-mode analysis}

A dendrogram (hierarchical clustering) is capable of decomposing data objects into several levels of nested partitioning (as a tree of clusters). Clustering of the data objects is carried out by cutting the dendrogram at the desired level, where each connected component forms a cluster. Ward's method is a variance-based method derived from agglomerative hierarchical clustering [29]. Variance methods generate clusters to minimize the intracluster variance $[11,40,42]$. For each cluster, the sum of 

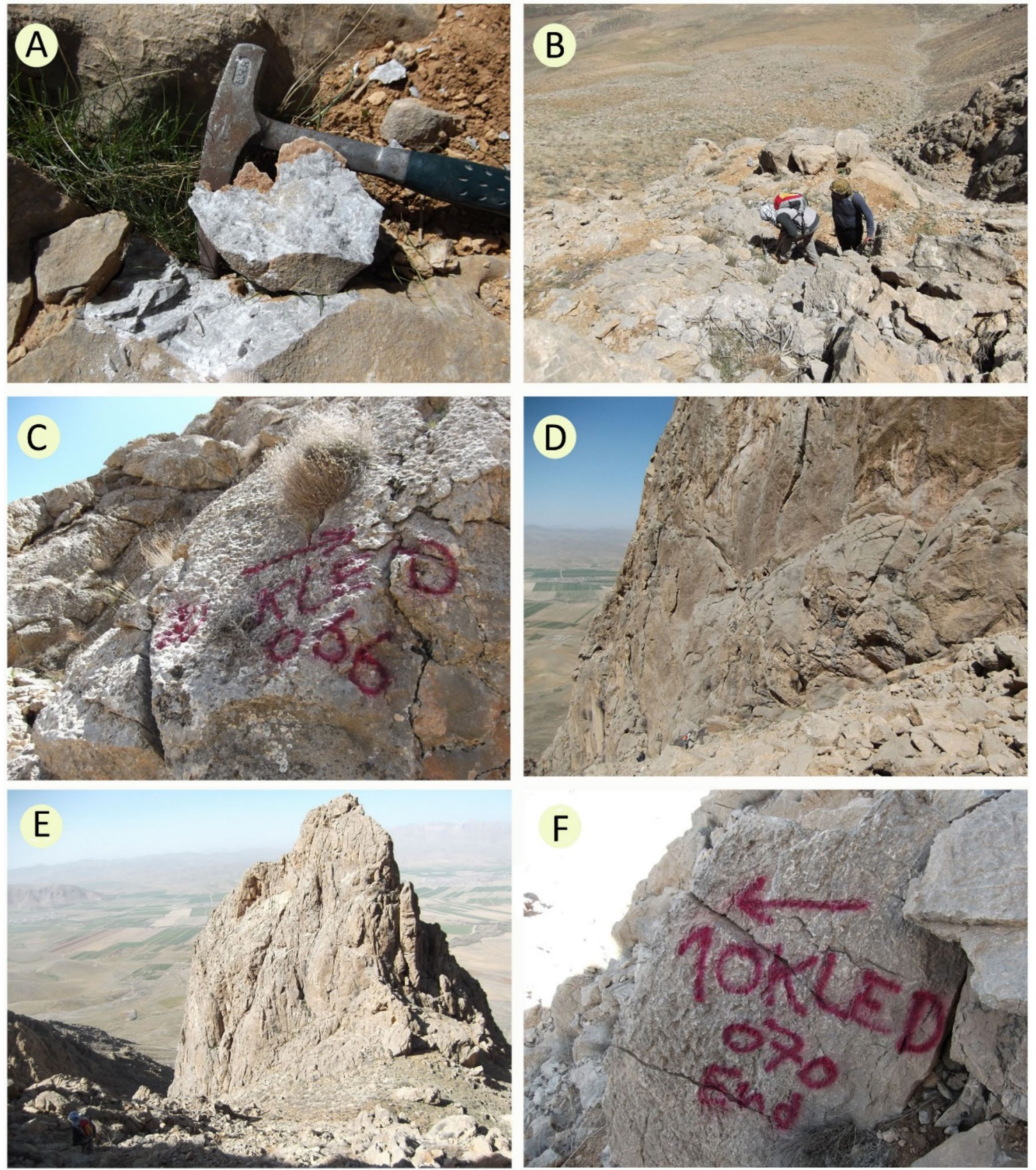

Fig. 5 a An image of sample 10 K-LED063 at its location, b sampling location of $10 \mathrm{~K}$-LED065, $\mathbf{c}$ image of starting point of sample 10 K-LED066, d overview of the location for sample $10 \mathrm{~K}$-LED068, e

squares is calculated, and the two clusters with the smallest increase in the overall sum of squares within cluster distances are combined. Ward's method and the average linkage method have been shown to perform better than the other procedures [35, 39].

Clustering is the classification of objects into different groups, or more precisely, the partitioning of a data set into subsets (clusters), so that the data in each overview of the location for samples 10 K-LED069 and 10 K-LED068, F) image of sampling end point for Sample 10 K-LED070 in Seghalat profile

subset could share some common similarity according to some defined distance measure $[3,4,12,31]$. Factor analysis takes as input a large number of variables and describes them with small number of factors in order to reduce the data dimension $[1,2,18,20]$. Appropriate factors should provide an easy interpretation of the data to make geological sense. In addition, simple presentation of anomalies, elemental association, and represent 
Fig. 6 Stratigraphical column with rock units in the Seghalat profile

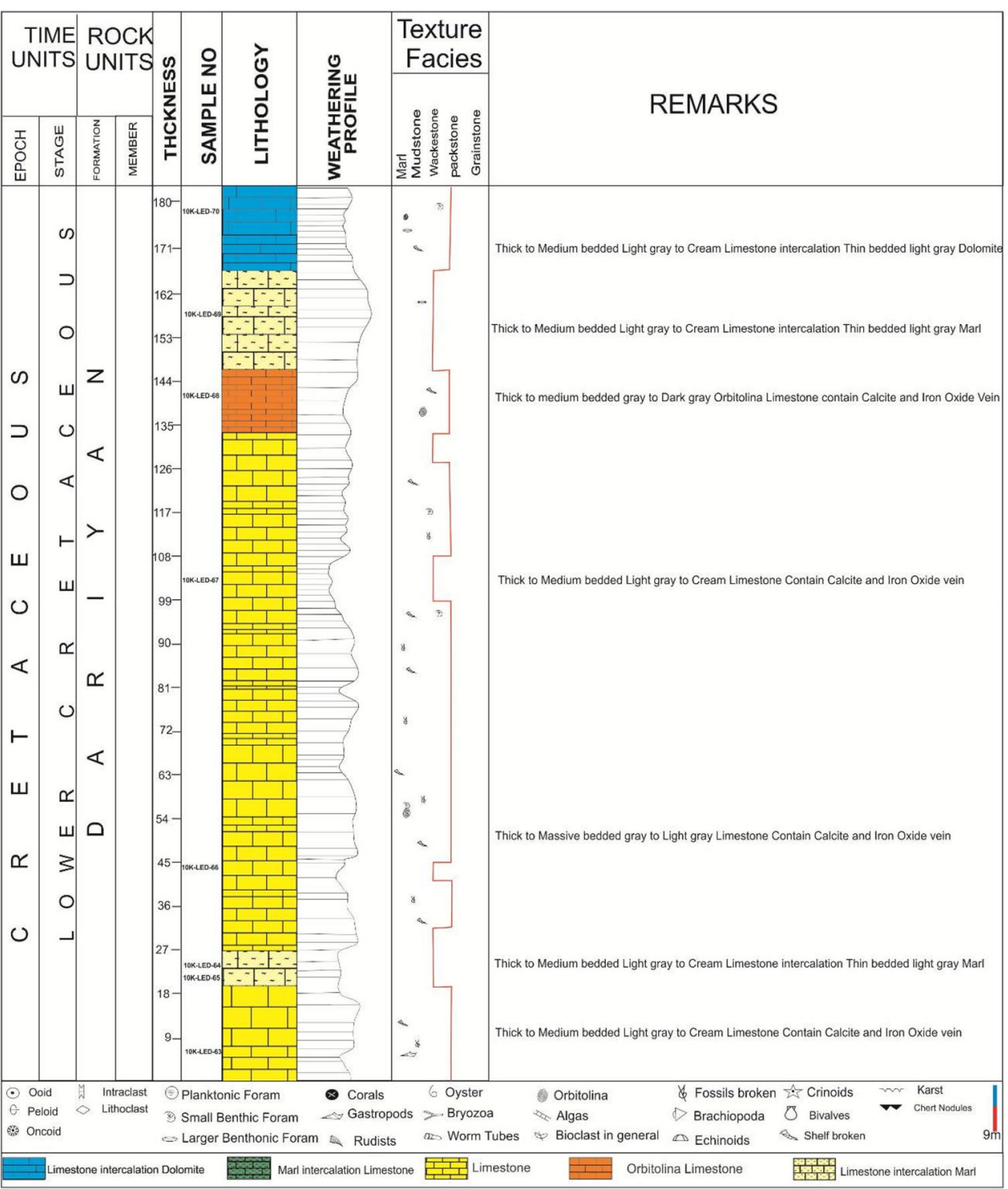

indicative samples are the other benefits of the multivariate method.

\subsection{K-Means clustering}

The k-means method is an algorithm that clusters $n$ given objects into $k$ partitions based on their attributes, where $k<n$. It is similar to the expectation-maximization algorithm for mixtures of Gaussians in that they both attempt to find the centers of natural clusters in the data $[13,24]$.

K-Means algorithm is useful for undirected knowledge discovery and is relatively simple. K-Means has found widespread usage in many fields such as unsupervised learning of neural network, classification analysis, pattern recognitions, image processing, machine vision, and artificial intelligence [16]. Each cluster is represented by the center of the cluster, and the algorithm converges to stable centriods of clusters. The most commonly used measure of similarity is the Euclidean distance.

\section{Discussion and results}

\subsection{Statistical parameter}

A number of statistical concepts such as mean, standard deviation, variance, minimum, first quartile, median, third quartile, and maximum of the most important elements are given in Table 2. It can be seen that the total mean of $\mathrm{CaCO}_{3}$ is close to $93 \%$ and its standard deviation is 11.795 . In addition, 25\% (first quartile) of the $\mathrm{CaCO}_{3}$ data are lower than $95.93 \%$, and $25 \%$ more than $97.657 \%$. The variations of $\mathrm{CaCO}_{3}$ concentration with respect to standard deviation are depicted in Fig. 7 , showing changes between $<-2.8$ SD 
Table 2 Statistical properties of the data set in the Dezak area

\begin{tabular}{lllllllll}
\hline Variable & Mean & SD & Variance & Minimum & Q1 & Median & Q3 & Maximum \\
\hline $\mathrm{CaCO}_{3}$ & 92.958 & 11.795 & 139.125 & 36.209 & 95.931 & 97.178 & 97.657 & 98.771 \\
$\mathrm{SiO}_{2}$ & 3.501 & 7.085 & 50.194 & 0.08 & 0.68 & 0.98 & 1.78 & 43.26 \\
$\mathrm{Al}_{2} \mathrm{O}_{3}$ & 0.9052 & 1.896 & 3.595 & 0.01 & 0.16 & 0.25 & 0.41 & 9.42 \\
$\mathrm{Fe}_{2} \mathrm{O}_{3}$ & 0.3702 & 0.763 & 0.5822 & 0.03 & 0.09 & 0.12 & 0.17 & 4.82 \\
$\mathrm{Na}_{2} \mathrm{O}$ & 0.03596 & 0.04557 & 0.00208 & 0.01 & 0.02 & 0.02 & 0.03 & 0.36 \\
$\mathrm{~K}_{2} \mathrm{O}$ & 0.165 & 0.2867 & 0.0822 & 0.01 & 0.04 & 0.06 & 0.1175 & 1.85 \\
$\mathrm{MgO}$ & 0.7477 & 0.4271 & 0.1824 & 0.31 & 0.51 & 0.595 & 0.78 & 3.42 \\
$\mathrm{TiO}_{2}$ & 0.04756 & 0.08429 & 0.0071 & 0.008 & 0.017 & 0.02 & 0.025 & 0.536 \\
$\mathrm{MnO}^{0.02099}$ & 0.017729 & 0.000314 & 0.014 & 0.015 & 0.016 & 0.017 & 0.24 \\
\hline
\end{tabular}

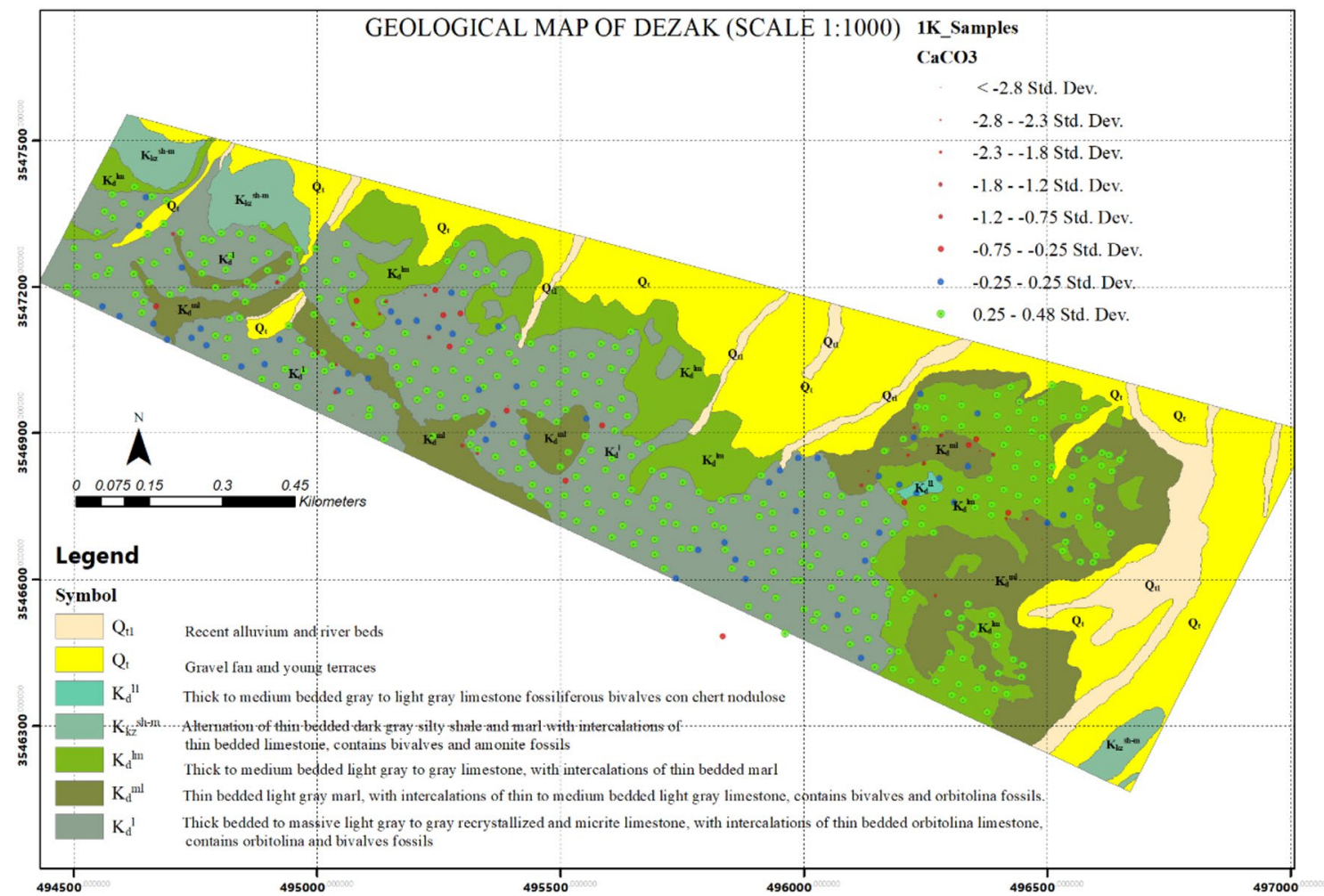

Fig. 7 Changes in $\mathrm{CaCO}_{3}$ concentration based on standard deviation

and $0.25-0.48$ SD. Therefore, left-skewness (with a left tail thicker than that of a normal distribution) is identified by negative values for $\mathrm{CaCO}_{3}$.

The lowest $\mathrm{CaCO}_{3}$ concentration is $36.209 \%$ (Table 2). Since the average $\mathrm{CaCO}_{3}$ concentration is $93 \%$ and the mean concentration is $97.65 \%$, most data are in the positive range of the average value (Fig. 8). Kriging estimation of $\mathrm{CaCO}_{3}$ based on fractal distribution of data is shown in Fig. 8. Few data are in a range lower than $\bar{x}-2.8 s$, and most have values greater than $\bar{x}-0.25 \mathrm{~s}$.

Furthermore, the variations in the concentration of $\mathrm{SiO}_{2}$ are plotted based on half of the standard deviation
(Fig. 9), where the kriging estimation was carried out with a search radius of $50 \mathrm{~m}$. Due to the sensitivity and effects of penalties on the high-grade $\mathrm{CaO}$ zone, the estimations were carried by using just one sample from each side. The average concentration of $\mathrm{SiO}_{2}$ falls in the first range of standard deviation $(\bar{x} \pm 0.25 \mathrm{~s})$, and with gradual changes up to $\bar{x}+2.7 \mathrm{~s}$, the concentration increases from 0.18 to $37.41 \%$ (Fig. 9). The gradual concentration changes in $\mathrm{Fe}_{2} \mathrm{O}_{3}, \mathrm{Al}_{2} \mathrm{O}_{3}, \mathrm{MgO}, \mathrm{K}_{2} \mathrm{O}$, and $\mathrm{Na}_{2} \mathrm{O}$ are shown in the ranges of 0.03-4.82, 0.02-9.25, 0.31-2.55, $0.01-1.85$, and $0.01-0.33 \%$ of the variations, respectively. 


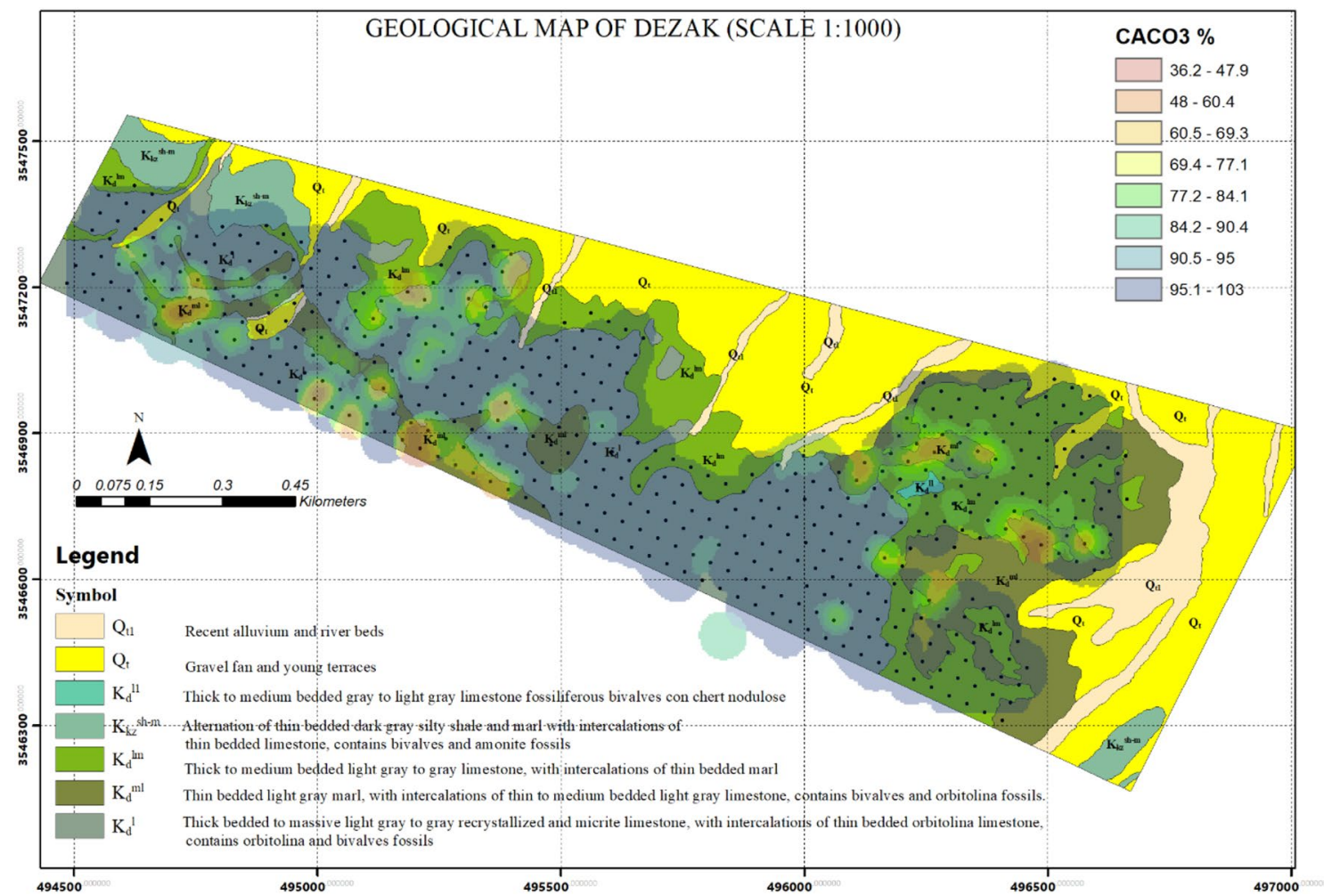

Fig. 8 Kriging estimation of $\mathrm{CaCO}_{3}$ based on fractal distribution of data

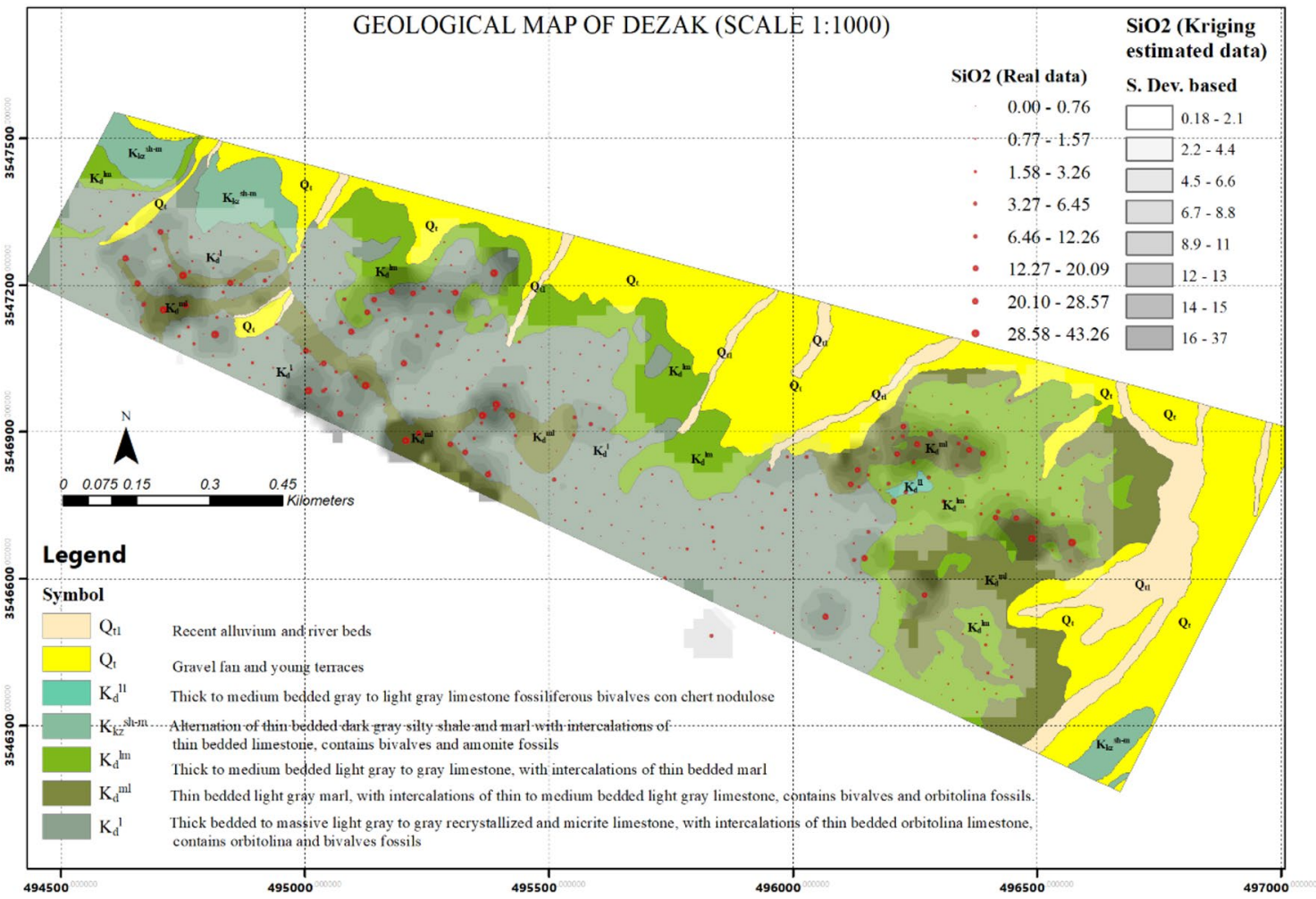

Fig. $9 \mathrm{SiO}_{2}$ concentration changes based on standard deviation 


\subsection{Geochemical multivariate analysis}

\subsubsection{Hierarchical clustering and factor analysis}

Clustering and factor analysis were performed on all the 492 samples obtained from a systematic grid sampling. Ward's agglomerative clustering starts with $\mathrm{CaCO}_{3}$ and LOI in a separate cluster for the Dezak samples. On the other hand, $\left(\mathrm{SiO}_{2}, \mathrm{Al}_{2} \mathrm{O}_{3}\right)-\left(\mathrm{Fe}_{2} \mathrm{O}_{3}, \mathrm{TiO}_{2}\right)-\mathrm{K}_{2} \mathrm{O}$ are formed and linked to $\mathrm{MnO}$ due to maximum similarity. $\mathrm{Na}_{2} \mathrm{O}, \mathrm{MgO}$ and $\mathrm{P}_{2} \mathrm{O}_{5}$ are then added to them to increase the cluster sizes. All the mentioned components connected to $\mathrm{SO}_{3}$ according to having the smallest similarity. Eventually, the components $\left(\mathrm{SiO}_{2}, \mathrm{Al}_{2} \mathrm{O}_{3}\right)-\left(\mathrm{Fe}_{2} \mathrm{O}_{3}, \mathrm{TiO}_{2}\right)-\mathrm{K}_{2} \mathrm{O}, \mathrm{MnO}, \mathrm{Na}_{2} \mathrm{O}$, $\mathrm{MgO}, \mathrm{P}_{2} \mathrm{O}_{5}$, and $\mathrm{SO}_{3}$ were classified in the same cluster, such that its distance is maximum from $\mathrm{CaCo}_{3}$ (or equally, the similarity is a minimum value) (Fig. 10).

Using factor analysis, it was shown that the $\mathrm{CaCO}_{3}$ and LOI characteristics have the highest similarity and the most geochemical proximity (Fig. 11a). Due to the opposite eigenvectors (loading) of $\mathrm{SiO}_{2}, \mathrm{Al}_{2} \mathrm{O}_{3}, \mathrm{Fe}_{2} \mathrm{O}_{3}, \mathrm{~K}_{2} \mathrm{O}$, $\mathrm{MgO}, \mathrm{Na}_{2} \mathrm{O}, \mathrm{MnO}, \mathrm{TiO}_{2}, \mathrm{P}_{2} \mathrm{O}_{5}, \mathrm{SrO}$, and $\mathrm{SO}_{3}$ versus $\mathrm{CaCO}_{3}$, the lowest geochemical similarity and maximum separation distance between $\mathrm{CaCO}_{3}$ and other parameters were observed (Fig. 11a). Hence, with a decrease in $\mathrm{CaCO}_{3}$, the other parameters are more likely to increase. The intensity and weight of changes in the investigated characteristics or eigenvectors (R-mode analysis, Fig. 11a) can be fully investigated by another analysis that will determine the position of the samples revealed by eigenvalues (Q-mode analysis, Fig. 12a).

\subsubsection{K-Means analysis}

By incorporating the results of multivariate K-Means analysis into the graphical Q-mode factor analysis, the variability of the data could be categorized as four geochemical data sets (Fig. 13). The geochemical classification is based on the results of K-Means multivariate analysis. Based on the eigenvectors of the data in Fig. 11a and K-Means classification in Fig. 13, the second group shows a $\mathrm{CaCO}_{3}$ enrichment of above 97\%, while the first group indicates intermediate grades below 50\% (Fig. 14). The first geochemical group comprises 21 samples and contains the highest concentration of $\mathrm{SiO}_{2}$ with an average greater than 30\% (Table 3). The second group, which comprises 422 composite samples from the region, also contain high-concentration $\mathrm{CaCO}_{3}$ samples with an average value greater than $97 \%$ (Table 3). The average $\mathrm{SiO}_{2}$ concentration in these samples is $1 \%$, and the sum of $\mathrm{Al}_{2} \mathrm{O}_{3}$ and $\mathrm{Fe}_{2} \mathrm{O}_{3}$ is about $0.38 \%$ (Table 3 ). The second group has the lowest mean distance from the center (Fig. 13) as well as the highest $\mathrm{CaCO}_{3}$ concentration (97\%). It is observed that most of the samples are indicative of $\mathrm{CaCO}_{3}$ concentration and some samples show depletion. Sample Nos. S436 and S445 have the least $\mathrm{CaCO}_{3}$ concentration (Fig. 13). On the other hand, a limited number of samples (S150, S56, and S410) show the highest $\mathrm{SO}_{3}$ concentration in the area.

\subsubsection{Clr-transformed data analysis}

In the present manuscript, the authors have used the robust factor analysis (RFA), and RFA based on clr
Fig. 10 Ward linkage and correlation coefficient distance for Dezak samples

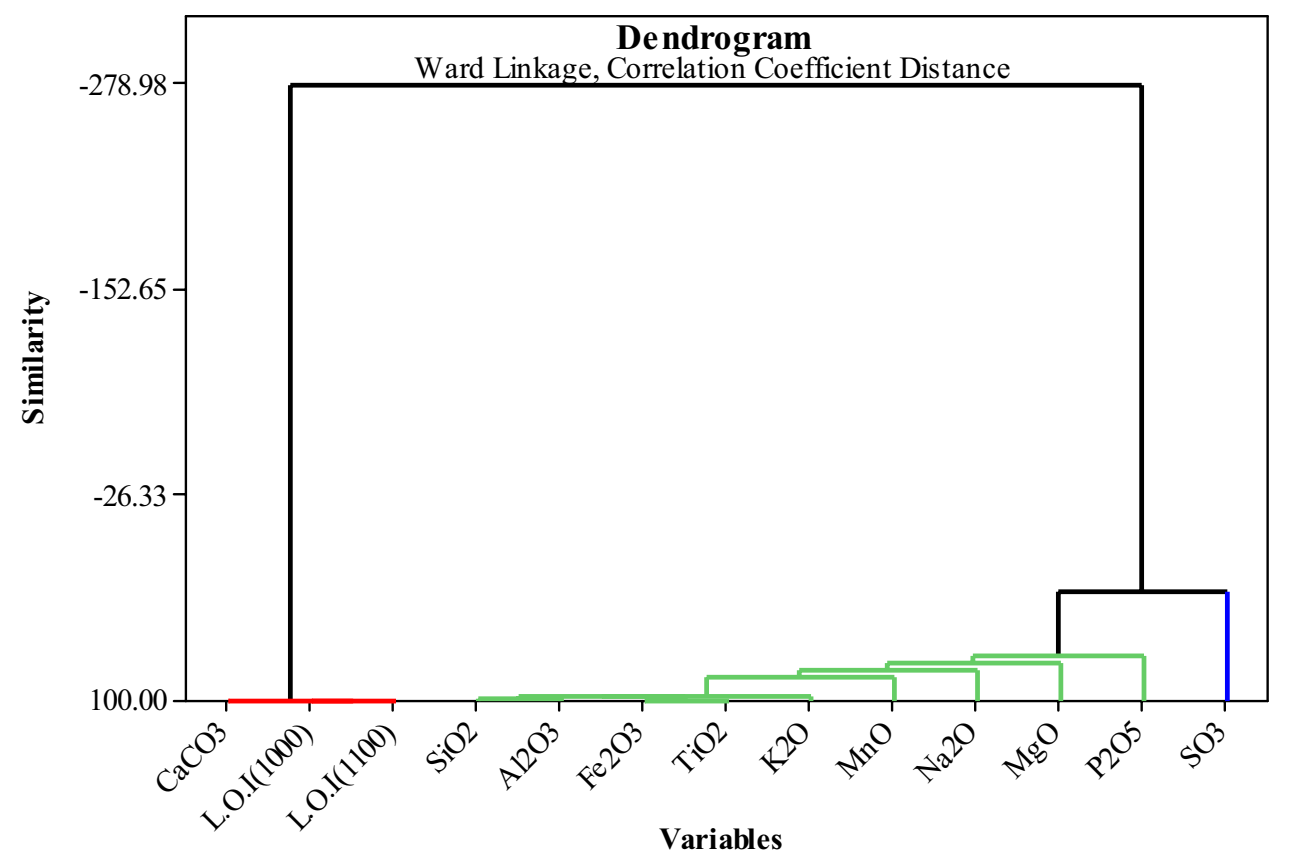


Fig. 11 Eigenvectors of geochemical parameters for normal scores data indicate $87 \%$ of variation (a) and clrtransformed data indicate $70 \%$ of variation (b) at Dezak area
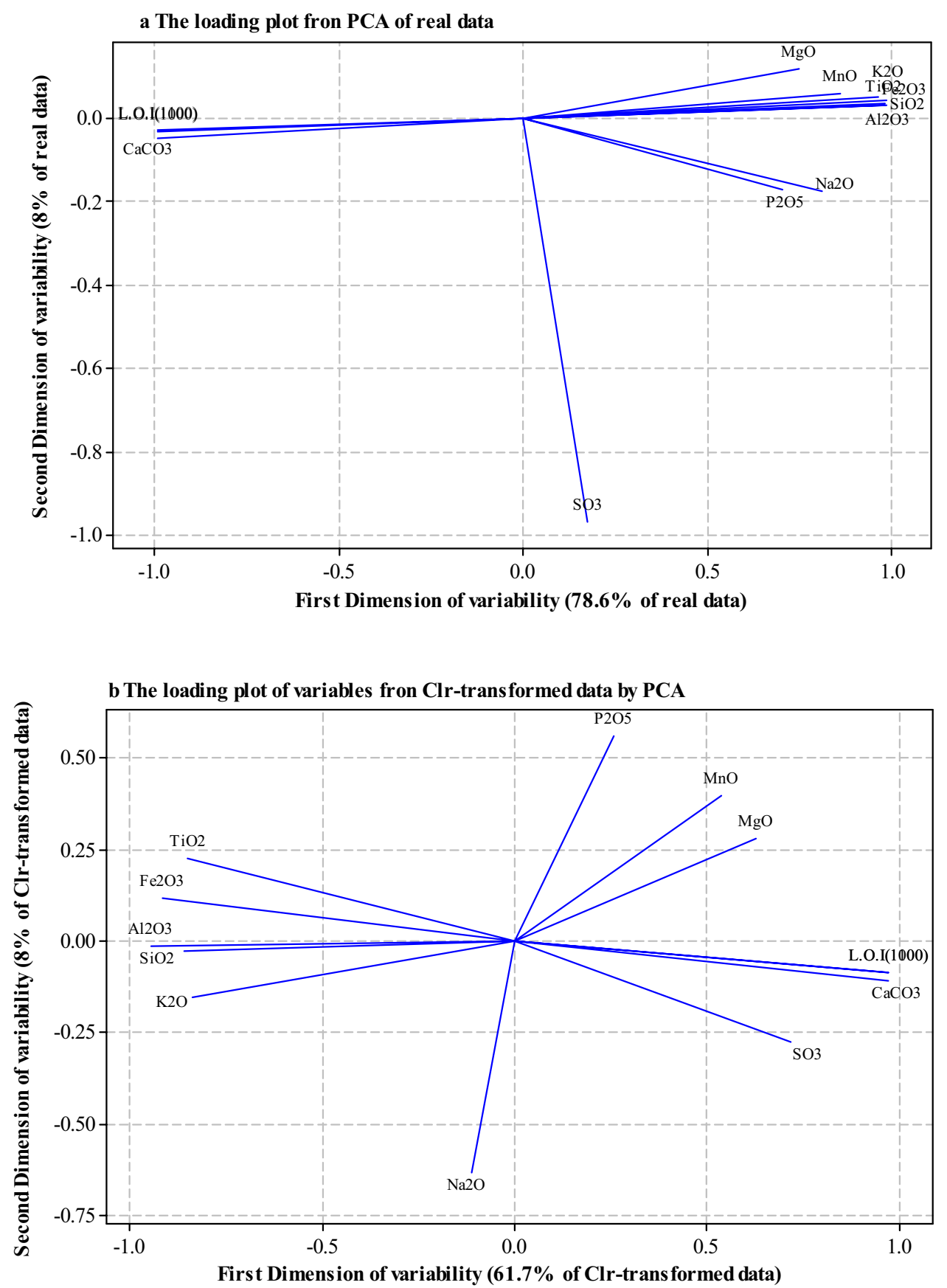

transformation in order to better elemental evaluation in Dezak area. By comparison of the results from R-mode on real data and R-mode on clr-transformed data, the closure effect is overcome. Where real data are opened by R-mode analysis, the eigenvectors maybe overlaid; while using compositional data transformed by log-ratio transformation, the eigenvectors show inherence. Log-ratio transformation analysis is sub-compositionally coherent so in this respect is better. This is because compositional data sum to $100 \%$ (closure), which explains why, e.g., $\mathrm{CaO}$ and LOls are on opposite sides of $\mathrm{PC} 1$ from $\mathrm{SiO}_{2}$, etc. The
R-mode analysis opened by real data is shown in Fig. 11 a, and it shows sub-compositional incoherence. For this normal score or the real data, the majority of the variations (78.6\%) are enclosed to first factor and all the vectors are separated in the semicircle.

By using clr-transformed data for R-mode analysis, the eigenvalues show sub-compositionally coherent and closure effect is overcomes. Accordingly, the total variance which is explained by the first factor decreases from $78.6 \%$ in real R-mode analysis to $61.7 \%$ in clr transformation (Fig. 11a, b). This is indicates the highest effect of 
Fig. 12 Eigenvectors of geochemical parameters and eigenvalues of 492 samples on the $\mathrm{PC} 1$ versus $\mathrm{PC} 2$ for normal scores data indicate $87 \%$ of variations (a) and clr-transformed data indicate $70 \%$ of variations (b) at Dezak area
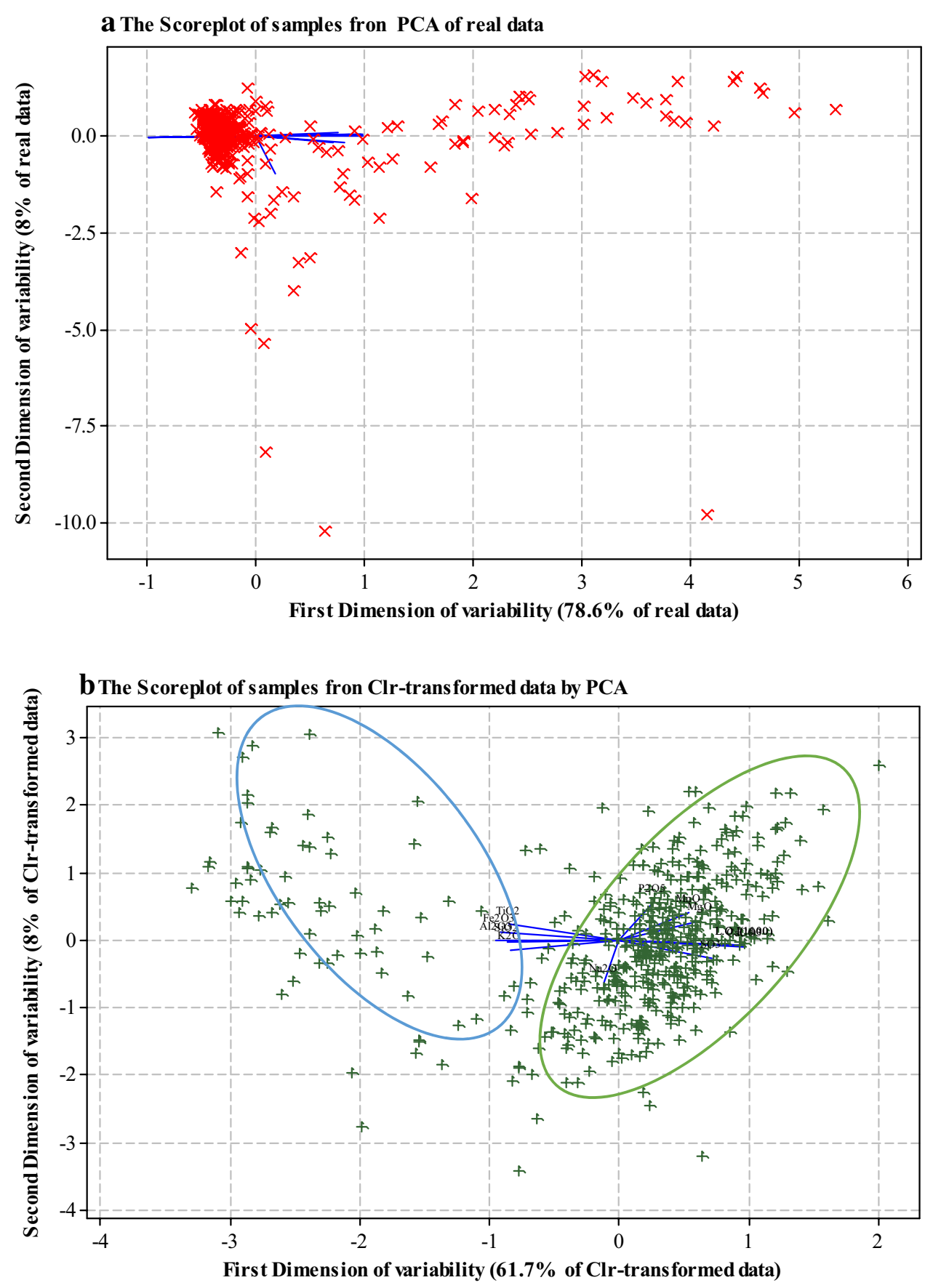

$\mathrm{CaCO}_{3}$ parameter for the first factor in the robust method (Fig. 11b). The results after transformation in R-mode analysis are mostly constrained and represented in a full circle.

Besides, the incoherence between scores of samples (Fig. 12a) was overcomes by clr transformation in Q-mode analysis (Fig. 12b). Finally, clr-transformed data indicate two population in Q-mode graphical representation, which is separated by distinct anisotropic clouds (Fig. 12b). Due to major occurrence of the first dimension, the geochemical changes are categorized as richest (the best data set), contaminated (the worst data set), and transmission zone (Fig. 15). The linkages between them are well explained as:

The best data set $=$ the richest rock units of limestone include $K_{d}^{1}$ and $K_{d}^{\mathrm{lm}}$

The transmission zone $=$ Marginal data or the $\mathrm{CaCO}_{3}$ unite with marl and Shale

The worst data set $=$ the light gray marl include $K_{d}^{\mathrm{ml}}$. 
Fig. 13 Q-mode of factor analysis accompanied by K-Means clustering

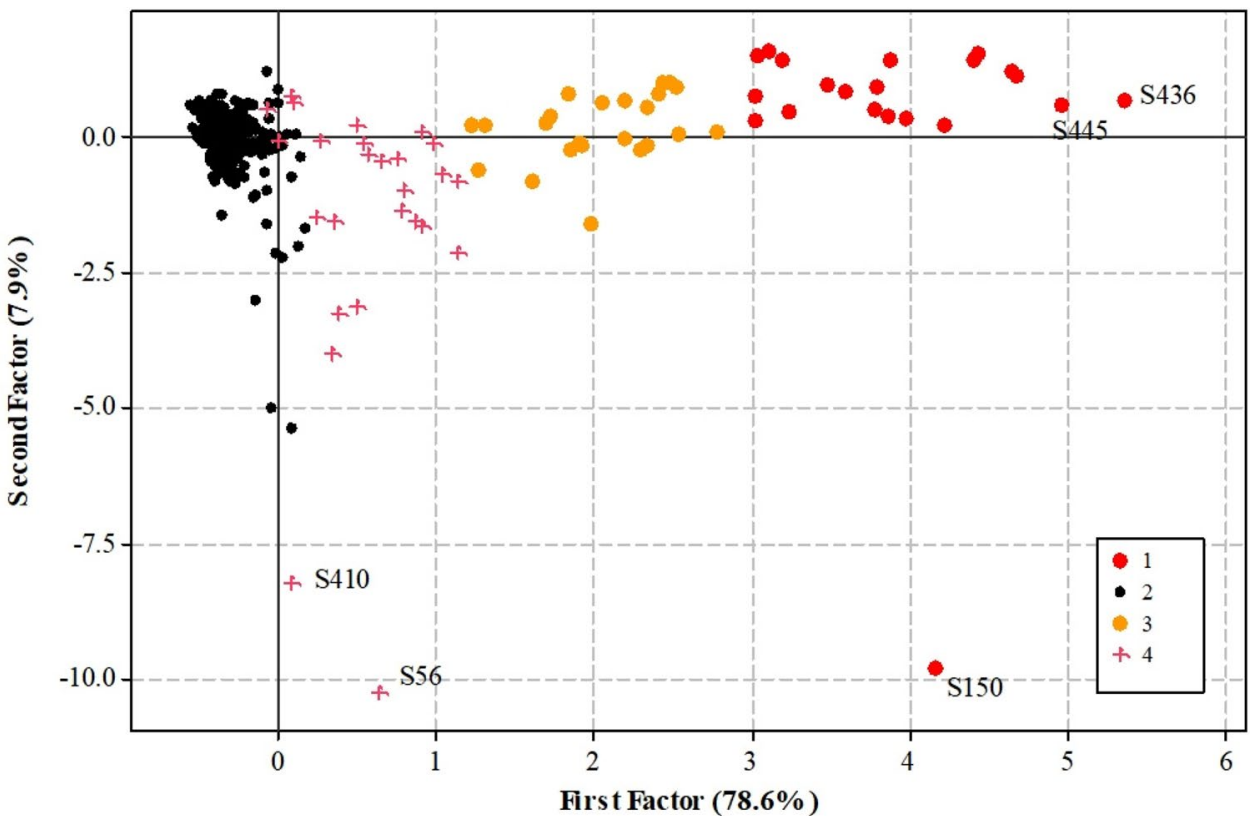

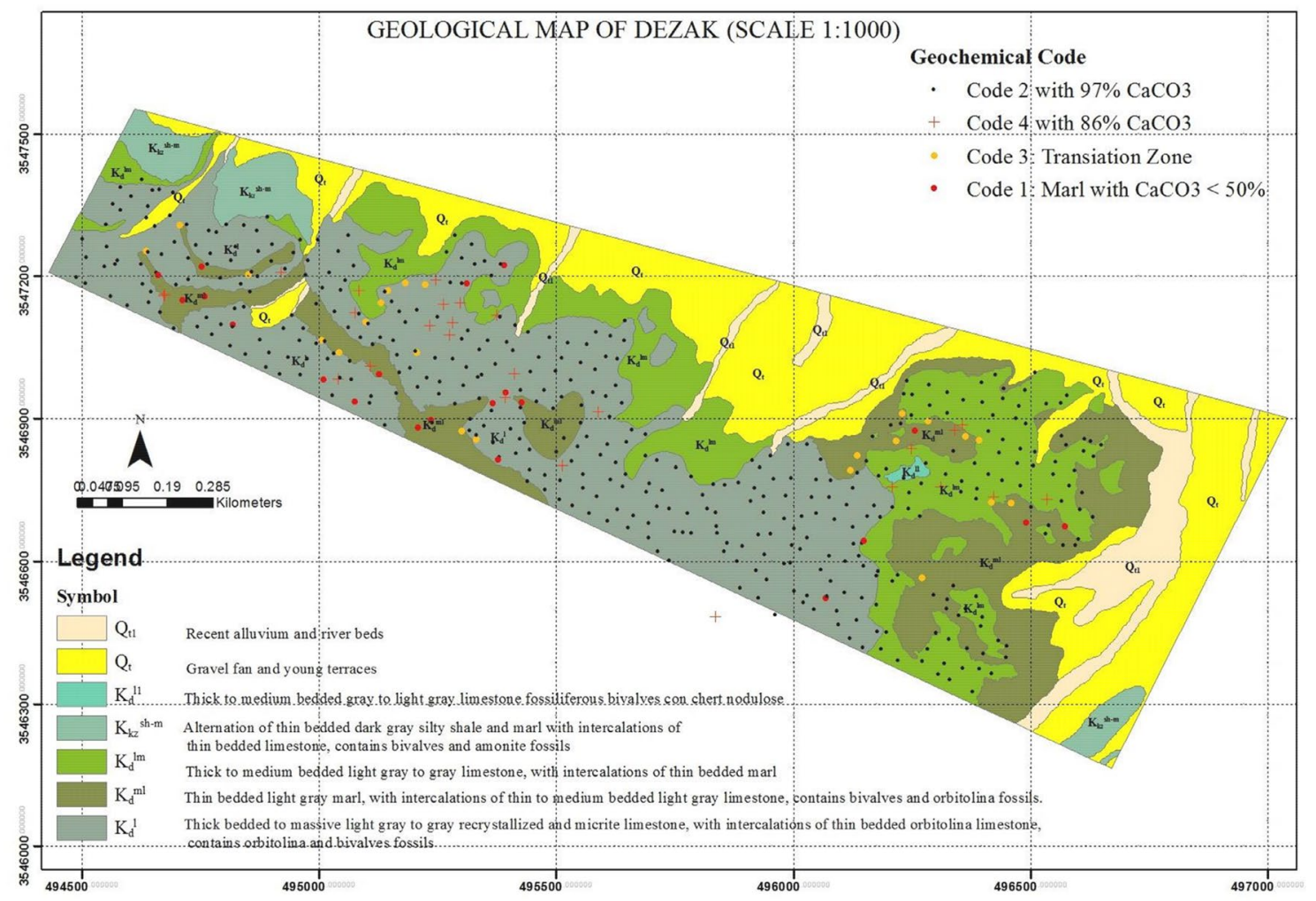

Fig. 14 Overlay clustering of the geological map using geochemical analysis. Code 2 with a CaCo3 concentration of higher than $97 \%$ is a considered an appropriate population

Interval plot of $\mathrm{CaCO}_{3}$ for groups obtained from multivariate K-Means analysis represents the mean value, and the mean value plus and minus the standard deviation $(x=\bar{x} \pm s)$, as shown in Fig. 16. The mean values observed in each group are the same as those previously calculated in Table 2 using the K-Means method. As seen, Cluster 2 shows the highest $\mathrm{CaCO}_{3}$ concentration (97.02\%; Fig. 16). The standard deviation of $\mathrm{CaCO}_{3}$ concentration in the second 
Table 3 Average concentration of variables in each cluster obtained from K-Means analysis

\begin{tabular}{lcccc}
\hline Variable & Cluster 1 & Cluster 2 & Cluster 3 & Cluster 4 \\
\hline $\mathrm{CaCO}_{3}$ & 48.0977 & 97.0268 & 66.9833 & 86.1376 \\
$\mathrm{SiO}_{2}$ & 30.3624 & 1.0568 & 18.7948 & 7.9554 \\
$\mathrm{Al}_{2} \mathrm{O}_{3}$ & 8.0571 & 0.2558 & 5.1374 & 1.9262 \\
$\mathrm{Fe}_{2} \mathrm{O}_{3}$ & 3.346 & 0.1221 & 1.8635 & 0.6731 \\
$\mathrm{Na}_{2} \mathrm{O}$ & 0.1795 & 0.0236 & 0.09 & 0.0727 \\
$\mathrm{~K}_{2} \mathrm{O}$ & 1.2357 & 0.072 & 0.7374 & 0.3031 \\
$\mathrm{MgO}$ & 1.9919 & 0.6503 & 1.38 & 0.765 \\
$\mathrm{TiO}_{2}$ & 0.3756 & 0.0202 & 0.2124 & 0.0805 \\
$\mathrm{MnO}$ & 0.0851 & 0.0164 & 0.0445 & 0.0234 \\
$\mathrm{P}_{2} \mathrm{O}_{5}$ & 0.112 & 0.0344 & 0.0877 & 0.0613 \\
$\mathrm{SO}$ & 0.03 & 0.0214 & 0.0282 & 0.0549 \\
$\mathrm{LOI}(1000)$ & 27.0507 & 43.149 & 33.9036 & 39.6584 \\
$\mathrm{LOI}(1100)$ & 27.2405 & 43.4084 & 34.0952 & 39.8542 \\
\hline
\end{tabular}

set of the data is 0.10 with a confidence level of $95 \%(\mathrm{Cl} \%)$. The values are calculated as follows:

$$
x=\bar{x}-s=97.02-0.10=96.92
$$$$
x=\bar{x}+s=97.02+0.10=97.12 \text {. }
$$

If the analyzed data have been investigated on the basis of field observations, based on the geochemical properties of the samples, these changes will show up according to the following groups in the area:

- The first group contains crystallized and micritic limestone (with numerous FeX and $\mathrm{Cal}$ veins and veinlets): This group with average $\mathrm{CaCO}_{3}$ and $\mathrm{SiO}_{2}$ concentrations of $30 \%$ and $48 \%$, respectively, belongs to the marl rocks. The highest amount of $\mathrm{Al}_{2} \mathrm{O}_{3}$ and $\mathrm{Fe}_{2} \mathrm{O}_{3}$ is also observed in this group, while the $\mathrm{MgO}$ content is about $2 \%$. This group is illustrated in Fig. 14 with a red circle. These samples have high overlap with the $K_{d}^{\mathrm{ml}}$ unit and represent marl samples. This layer is the transitional zone (code 1) and in field observation detected as marl or limestone and marl (mixed sample) samples.

- The second group contains about 50\% micritic limestone and $50 \%$ alluvial limestone, $<50 \%$ limestone, and probably chert-limestone: This group is illustrated in Fig. 14 with a black circle. These samples are highly uniform and have an overlap with the $K_{d}^{I m}$ and $K_{d}^{\prime}$ units. It can be seen that there exists an undesirable discrepancy between the $95 \% \mathrm{Cl}$ obtained from the 2 th group and the other three groups (Fig. 16). This group belongs to the high-quality limestone group in the area with

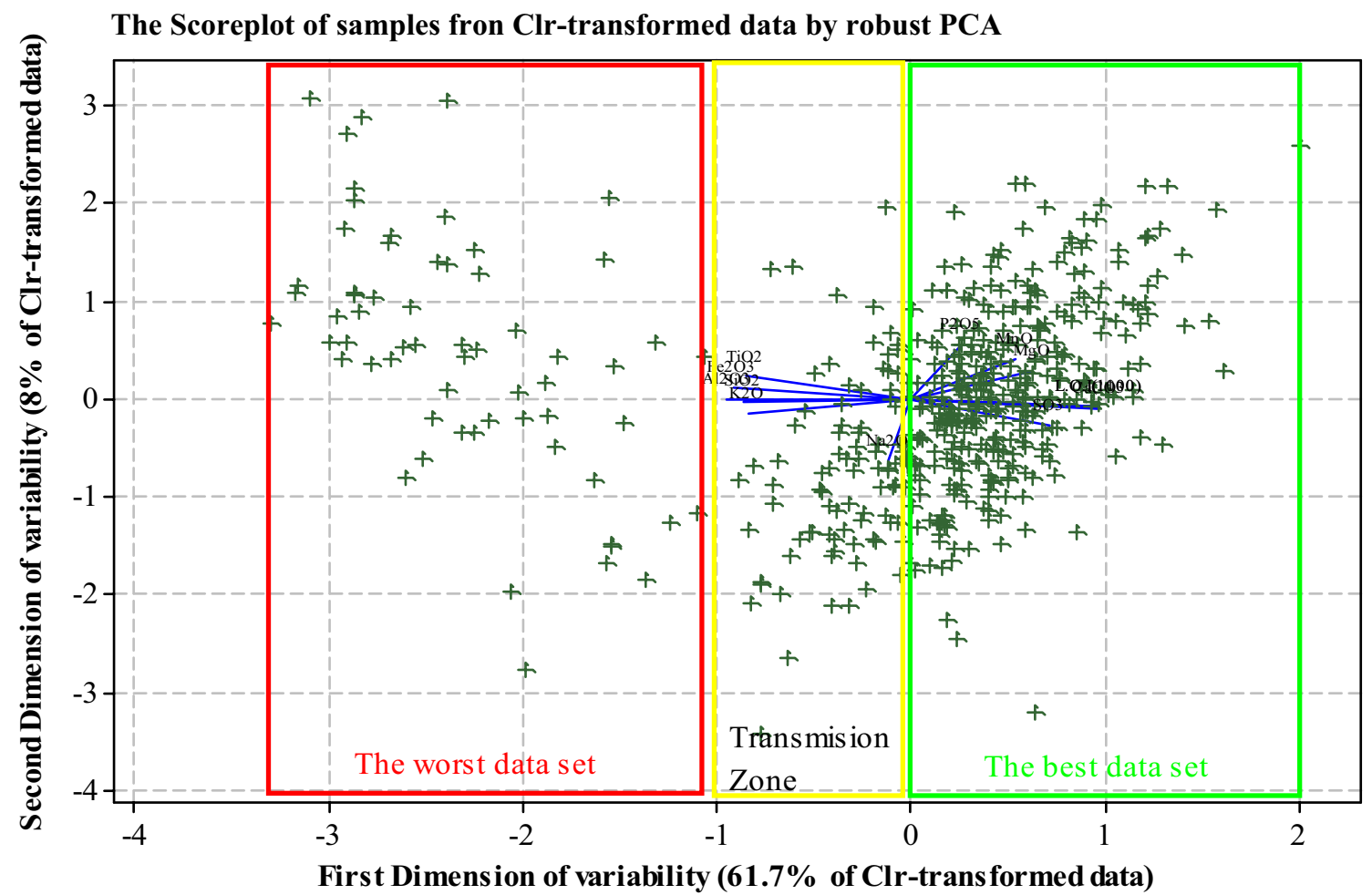

Fig. 15 Scores plot on the PC1 versus PC2 for clr-transformed data accompanied by categorized samples at Dezak area. Due to major occurrence of the first dimension, the geochemical changes cate- gorized as richest (the best data set), contaminated (the worst data set), and transmission zone 
Fig. 16 Interval plot of $\mathrm{CaCO} 3$ in five groups obtained from the multivariate K-Means analysis
Interval Plot of $\mathrm{CaCO} 3,95 \% \mathrm{CI}$ for the Mean

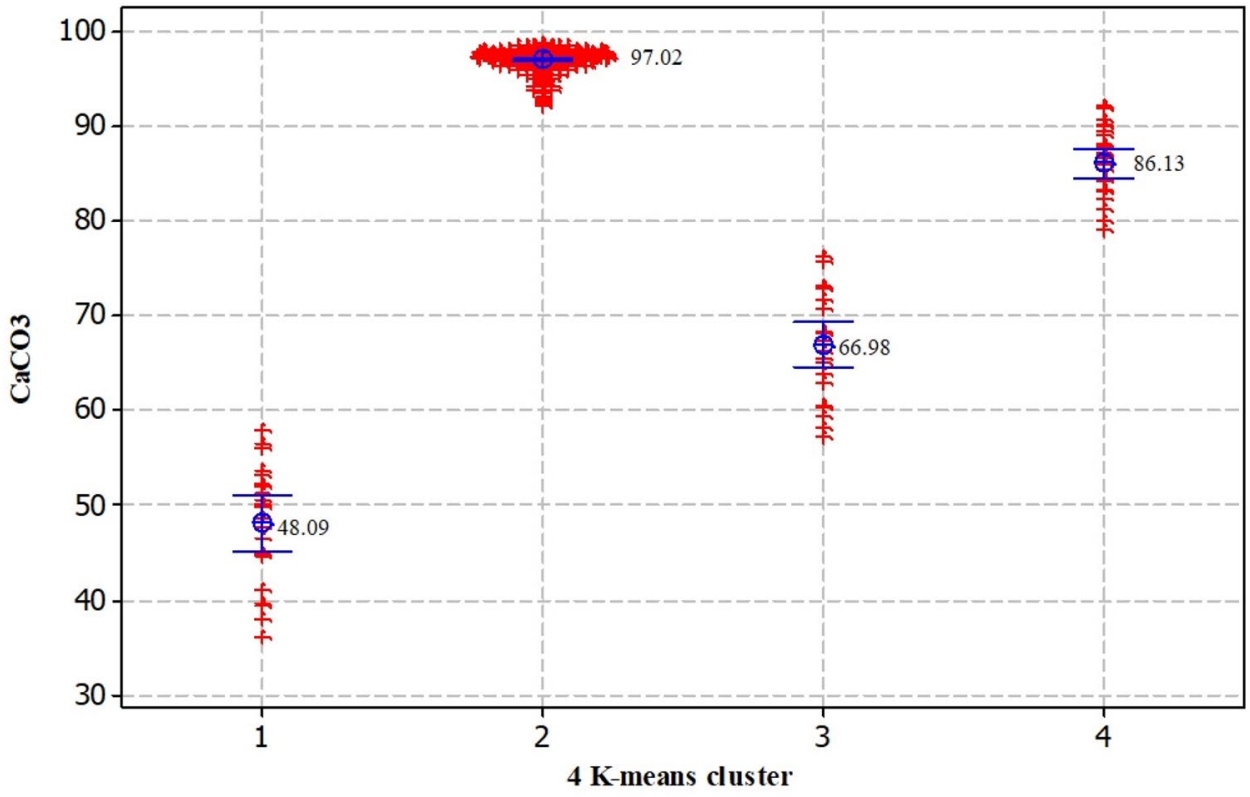

mean concentrations of $97 \%$ and $1 \%$ for $\mathrm{CaCO}_{3}$ and $\mathrm{SiO}_{2}$, respectively.

- The third group includes 50\% < marl, 50\% > debris and limestone (marl sample): With an average concentration of $67 \%$ and $19 \%$, respectively, for $\mathrm{CaCO}_{3}$ and $\mathrm{SiO}_{2}$, this group belongs to the intermediate or transition groups. This group is illustrated in Fig. 14 with a yellow symbol. These samples clearly indicate the boundaries of $K_{d}^{\mathrm{Im}}, K_{d}^{l}$, and $K_{d}^{\mathrm{ml}}$ units or a mixture of them.

- The fourth group consist of 1) $50 \%$ < crystallized limestone and micritic rocks and 50\% > marl and debris; 2 ) about 50\% chert-limestone and about 50\% marl and debris (mixed sample). The fourth geochemical group with an average concentration of $86 \%$ and nearly $8 \%$, respectively, for $\mathrm{CaCO}_{3}$ and $\mathrm{SiO}_{2}$ belongs to the poor quality limestone group of the region. This group is illustrated in Fig. 14 with a red symbol. Samples in this group are also located at the border, but are more inclined toward the $K_{d}^{I}$ and $K_{d}^{\mathrm{Im}}$ units.

The spatial plot of the samples in the area is depicted in Fig. 14. The second group (represented with Code 2) mainly consists of $K_{d}^{\mathrm{Im}}$ and $K_{d}^{\prime}$ lithologies. They were covered by thick- to medium-bedded light gray to gray limestone and thick-bedded massive light gray recrystallized and micrite limestone containing orbitalina and bivalves' fossils, respectively. Accordingly, comprehensive information can be obtained from the spatial position of the samples and lithologies. The first and third groups are relatively $\mathrm{CaCO}_{3}$-depleted samples. Therefore, each geochemical group that represents a certain concentration of its compounds is directly linked to a geological code. Thick- to medium-bedded gray (or light gray) limestone and thick-bedded light gray recrystallized and micrite limestone containing orbitalina and bivalve fossils.

\section{Conclusion}

This study concluded that the second group can be considered as the best plant feed from both spatial and geochemical perspectives. With a $\mathrm{CaCO}_{3}$ concentration of higher than $97 \%$ and $\mathrm{SiO}_{2}$ concentration lower than $1 \%$, this group was recognized as the high-quality limestone group in the area. These samples are highly uniform and overlap with $K_{d}^{\mathrm{Im}}$ and $K_{d}^{l}$ units, so thick-bedded gray (or light gray) agglomerated units of micritic and recrystallized limestone are the main important lithologies. This layer contains thin layers of orbitolina limestone containing orbitolina fossils. On the other hand, the $K_{d}^{\mathrm{ml}}$ unit revealed that marl layer is the transitional zone and is the most inappropriate feed layer. Due to the high overlap between the classified samples and the geological map, both of them are verified by remarkable note in package samples and visual properties; all the classifications have been confirmed. Moreover, geochemical analyses confirmed the geological properties in the area, such that $K_{d}^{\operatorname{lm}}$ and $K_{d}^{l}$ rock types from light gray to gray colors contained micritic and crystallized limestone as the most important units.

In order to overcome closure effect at the area, compositional clr transformation was done. Accordingly, 
semicircular eigenvector (loadings of elements) and eigenvalues (score plot of samples) in normal distribution could be seen in a circular and anisotropic distribution by clr transformation. Scores plot on the PC1 versus PC2 for clr-transformed data accompanied by categorized samples at Dezak area. Due to major occurrence of the first dimension, the geochemical changes categorized as richest (the best data set), contaminated (the worst data set), and transmission zone.

Acknowledgements The authors would like to acknowledge Dr. Farshad Darabi-Golestan from the Amirkabir University of Technology for his remarkable contribution to make this paper as comprehensive as possible.

\section{Compliance with ethical standards}

Conflict of interest The authors have no affiliations with or involvement in any organization or entity with any financial interest, or nonfinancial interest in the subject matter or materials discussed in this manuscript.

\section{References}

1. Afzal P, Heidari SM, Ghaderi M, Yasrebi AB (2017) Determination of mineralization stages using correlation between geochemical fractal modeling and geological data in Arabshah sedimentary rock-hosted epithermal gold deposit, NW Iran. Ore Geol Rev 91:278-295

2. Afzal P, Jebeli M, Pourkermani M, Jafari Rad A (2018) Correlation between rock types and Copper mineralization using fractal modeling in Kushk-e-Bahram deposit, Central Iran. Geopersia 8(1):131-141

3. Afzal P, Mirzaei M, Yousefi M, Adib A, Khalajmasoumi M, Zarif AZ, Foster P, Yasrebi AB (2016) Delineation of geochemical anomalies based on stream sediment data utilizing fractal modeling and staged factor analysis. J Afr Earth Sci 119:139-149

4. Afzal P, Yusefi M, Mirzaie M, Ghadiri-Sufi E, Ghasemzadeh S, Daneshvar Saein L (2019) Delineation of podiform-type chromite mineralization using geochemical mineralization prospectivity index and staged factor analysis in Balvard area (SE Iran). J Min Environ 10(3):705-715

5. Aitchison J (1986) The statistical analysis of compositional data: monographs on Statistics and Applied Probability, no. Chapman \& Hall Ltd., London (Reprinted in $\mathbf{2 0 0 3}$ with additional material by The Blackburn Press)

6. Aitchison J, Greenacre M (2002) Biplots of compositional data. J R Stat Soc Ser C (Appl Stat) 51(4):375-392

7. Alizadeh B, Sarafdokht $H$, Rajabi M, Opera A, Janbaz M (2012) Organic geochemistry and petrography of Kazhdumi (AlbianCenomanian) and Pabdeh (Paleogene) potential source rocks in southern part of the Dezful Embayment, Iran. Org Geochem 49:36-46

8. Carranza EJM (2016) Geochemical mineral exploration: should we use enrichment factors or log-ratios? Nat Resour Res 26:411-428

9. Darabi-Golestan F, Ghavami Riabi R, Majlesi MJ, Memarzade M, Asadi Harooni H (2012) Identify and separation of anomall variable using correspondence and discriminant analyses methods at Northern-Dalli area. Anal Numer Method Min Eng 3:35-45 (in persion)

10. Darabi-Golestan F, Hezarkhani A (2018) Evaluation of elemental mineralization rank using fractal and multivariate techniques and improving the performance by log-ratio transformation. J Geochem Explor 189:11-24

11. Darabi-Golestan F, Hezarkhani A (2019) Multivariate analysis of log-ratio transformed data and its priority in mining science, porphyry and polymetallic vein deposits case studies. Bull Miner Res Explor 159:185-200

12. Darabi-Golestan F, Hezarkhani A (2019) Multivariate analysis of log-ratio transformed data and its priority in mining science: porphyry and polymetallic vein deposits case studies. Maden Tetkik ve Arama Dergisi 159(159):185-200

13. Darabi-Golestan F, Hezarkhani A (2020) Quality and quantity assessment using multivariate compositional and univariate analysis in the Glojeh polymetallic vein mineralization. Carbonates Evaporites 35(2):35

14. Ebrahimi B, Seif A (2016) Equilibrium-line altitudes of late quaternary glaciers in the Zardkuh Mountain, Iran. Geopersia 6(2):299-322

15. Egozcue JJ, Pawlowsky-Glahn V, Mateu-Figueras G, BarceloVidal C (2003) Isometric logratio transformations for compositional data analysis. Math Geol 35(3):279-300

16. El Maghraby A, Abdalla M, Enany O, El Nahas MY (2015) Detecting and tracking of multiple people in video based on hybrid detection and human anatomy body proportion. Int J Comput Appl 109(17):10-14

17. Filzmoser P, Hron K, Reimann C (2009) Principal component analysis for compositional data with outliers. Environmetrics 20(6):621-632

18. Fyzollahhi N, Torshizian H, Afzal P, Jafari MR (2018) Determination of lithium prospects using fractal modeling and staged factor analysis in Torud region, NE Iran. J Geochem Explor 189:2-10

19. Hamedanian MK, Vaziri SH, Shakarami MA, Arian M, Arzani N (2016) Microfacies, sedimentary environment and sequence stratigraphy of Gadvan and Darian Formations in the Zagros Basin, South of Semirom, Iran. Open J Geol 6(09):1169

20. Heidari SM, Ghaderi M, Afzal P (2013) Delineating mineralized phases based on lithogeochemical data using multifractal model in Touzlar epithermal Au-Ag (Cu) deposit, NW Iran. Appl Geochem 31:119-132

21. Huang J, Qiu Y, Guo X (2009) Cluster and discriminant analysis of electrochemical noise statistical parameters. Electrochim Acta 54(8):2218-2223

22. Iwamori H, Yoshida $K$, Nakamura $H$, Kuwatani $T$, Hamada $M$, Haraguchi S, Ueki K (2017) Classification of geochemical data based on multivariate statistical analyses: complementary roles of cluster, principal component, and independent component analyses. Geochem Geophys Geosyst 18(3):994-1012

23. Jenkins $S$ (2016) Precipitated calcium carbonate from limestone. Chem Eng 123(6):36

24. Kanungo T, Mount DM, Netanyahu NS, Piatko CD, Silverman R, Wu AY (2002) An efficient k-means clustering algorithm: analysis and implementation. IEEE Trans Pattern Anal Mach Intell 24(7):881-892

25. Kevorkijan V (2010) Low cost aluminium foams made by $\mathrm{CaCO} 3$ particulates. Assoc Metall Eng Serb AMES 13:205-219

26. Kim JJ, Ahn JW, Lee MW, Lee JK, Seo YB (2012) Improving recycled fibres in printing paper by application of an in situ $\mathrm{CaCO} 3$ formation method. I. Process effects. Appita J Tech Assoc Aust N Z Pulp Pap Ind 65(4):347

27. Kosari E, Kadkhodaie A, Bahroudi A, Chehrazi A, Talebian M (2017) An integrated approach to study the impact of fractures distribution on the Ilam-Sarvak carbonate reservoirs: a case 
study from the Strait of Hormuz, the Persian Gulf. J Pet Sci Eng 152:104-115

28. Makvandi S, Ghasemzadeh-Barvarz M, Beaudoin G, Grunsky EC, McClenaghan MB, Duchesne C, Boutroy E (2016) Partial least squares-discriminant analysis of trace element compositions of magnetite from various VMS deposit subtypes: application to mineral exploration. Ore Geol Rev 78:388-408

29. Murtagh $F$, Legendre $P$ (2014) Ward's hierarchical agglomerative clustering method: which algorithms implement Ward's criterion? J Classif 31(3):274-295

30. Naderi-Khujin M, Seyrafian A, Vaziri-Moghaddam H, Tavakoli V (2016) A record of global change: OAE 1a in Dariyan shallowwater platform carbonates, southern Tethys, Persian Gulf, Iran. Facies 62(4):25

31. Ostadhosseini A, Barati M, Afzal P, Lee I (2018) Prospecting polymetallic mineralization in Ardestan area, Central Iran, using fractal modeling and staged factor analysis. Geopersia 8(2):279-292

32. Rahmani O, Aali J, Mohseni H, Rahimpour-Bonab H, Zalaghaie $\mathrm{S}$ (2010) Organic geochemistry of Gadvan and Kazhdumi formations (Cretaceous) in South Pars field, Persian Gulf, Iran. J Pet Sci Eng 70(1-2):57-66

33. Rezaeeparto K, Rahimpour BH, Kadkhodaie A, Arian M, Hajikazemi $E$ (2015) Investigation of microfacies, sedimentary environment and diagenesis processes of dariyan reservoir in salman oil field. Geosciences 25(97):267-278

34. Shah MH, Shaheen N (2008) Annual and seasonal variations of trace metals in atmospheric suspended particulate matter in Islamabad, Pakistan. Water Air Soil Pollut 190(1-4):13-25

35. Szekely GJ, Rizzo ML (2005) Hierarchical clustering via joint between-within distances: extending Ward's minimum variance method. J Classif 22(2):151-183

36. Thió-Henestrosa S, Martín-Fernández J (2005) Dealing with compositional data: the freeware CoDaPack. Math Geol 37(7):773-793
37. Torghabeh AK, Pimentel N (2016) Paleogeography and sequence stratigraphy in Dariyan Carbonate Reservoir, NE Shiraz. Open J Geol 6(11):1423

38. Tsagris MT, Preston S, Wood AT (2011) A data-based power transformation for compositional data: arXiv preprint arXiv:1106.145

39. Wang L, Wu C, Gu X, Liu H, Mei G, Zhang W (2020) Probabilistic stability analysis of earth dam slope under transient seepage using multivariate adaptive regression splines. Bull Eng Geol Environ 79:2763-2775

40. Yasrebi AB, Wetherelt A, Foster PJ, Afzal P, Coggan J, Ahangaran DK (2013) Application of RQD-Number and RQD-Valume multifractal modelling to deleniate rock mass characterisation in Kahang Cu-Mo porphyry deposit, Central Iran. Arch Min Sci 58(4):1023-1035

41. Zappa W (2012) Pilot-scale experimental work on the production of precipitated calcium carbonate (PCC). Chem Eng J 192:77-89

42. Zhang W, Zhang R, Wang W, Zhang F, Goh ATC (2019) A multivariate adaptive regression splines model for determining horizontal wall deflection envelope for braced excavations in clays. Tunn Undergr Space Technol 84:461-471

43. Zhang W, Zhang Y, Goh AT (2017) Multivariate adaptive regression splines for inverse analysis of soil and wall properties in braced excavation. Tunn Undergr Space Technol 64:24-33

44. Zuo R, Xia Q, Wang H (2013) Compositional data analysis in the study of integrated geochemical anomalies associated with mineralization. Appl Geochem 28:202-211

Publisher's Note Springer Nature remains neutral with regard to jurisdictional claims in published maps and institutional affiliations. 